\title{
Paideusis
}

\section{Records of Pupil Achievement: Some Philosophical Issues}

\section{David Bridges}

Volume 5, Number 2, 1992

URI: https://id.erudit.org/iderudit/1073347ar

DOI: https://doi.org/10.7202/1073347ar

See table of contents

Publisher(s)

Canadian Philosophy of Education Society

ISSN

0838-4517 (print)

1916-0348 (digital)

Explore this journal

Cite this article

Bridges, D. (1992). Records of Pupil Achievement: Some Philosophical Issues.

Paideusis, 5(2), 15-24. https://doi.org/10.7202/1073347ar

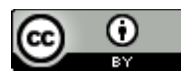

This document is protected by copyright law. Use of the services of Erudit (including reproduction) is subject to its terms and conditions, which can be viewed online.

https://apropos.erudit.org/en/users/policy-on-use/
This article is disseminated and preserved by Érudit.

Érudit is a non-profit inter-university consortium of the Université de Montréal, Université Laval, and the Université du Québec à Montréal. Its mission is to promote and disseminate research.

https://www.erudit.org/en/ 


\section{Records of Pupil Achievement: Some Philosophical Issues}

\section{David Bridges, University of East Anglia}

\section{Introduction}

Some excursions into philosophy of education start from mainstream philosophical writing which is applied to educational issues, while others are responses to earlier writing in philosophy of education. This paper is, however, rooted in empirical investigation of a recent government initiative in pupil assessment and has, I believe, two particular points of interest which are owed to these roots.

The first is that it illustrates the way in which philosophical issues doggedly surface out of educational practice and deeply impregnate education discourse (if someone has the wit to recognise them) even as governments drive philosophy out of the curriculum of teacher education and ministers dismiss it in the terms of the Secretary of State for Education in England, Kenneth Clarke, as "barmy theory."

The second interest is that it indicates that there is neglected territory in philosophy of education, which is that of student assessment-a subject upon which deeper misconceptions are held, higher expectations entertained, and more resources wasted than any other in education.

The starting point for this discussion was, then, a national initiative in England and Wales to introduce records of pupil achievement (RPAs)-also referred to as records of achievement (ROAs) and pupil profiles-into schools. More specifically, the observations which follow derive from an evaluation of a pilot scheme for records of achievement introduced in the county of Suffolk in East Anglia ${ }^{1}$-work which led in turn to a series of consultations with the team responsible for the national evaluation of the pilot schemes ${ }^{2}$.

In all this work, we were occupied with very practical issues. What approach are schools adopting? What actually happens? How is time found? What is the role of the class teacher? The RPA co-ordinator? What skills do they require? How does the RPA relate to the curriculum? To the pastoral structure? What do pupils/teachers/parents/employers think of it all? and so on.

But, inevitably for people thinking seriously about these questions, more fundamental philosophical questions kept surfacing about values, meaning, truth, and validity and about human nature. They were, however, practical questions, too, in the sense that the way in which teachers answered them made a difference to practice, that differences of view about practice were rooted in them, and that puzzlement about these matters underlay uncertainty about what to do. The concern of this paper is to illustrate and to begin to explore these issues.

\section{What are records of pupil achievement?}

The story of RPAs in British experience has sometimes ${ }^{3}$ been traced to the 1963 Newsom Report, ${ }^{4}$ which suggested that "boys and girls who stay at school until they are sixteen may reasonably look for some record of achievement when they leave." Since then, some children have received at least an " $O$ " Level or Certificate of Secondary Education indicating a number of passes and grades. 
However, even those who have been most successful in these terms might reasonably have questioned whether this represented the sum total of their achievement. Others who left with little or no certificated achievement in these terms might reasonably but, perhaps incorrectly, have concluded that they had nothing to show for eleven years of schooling.

Increasingly during the 1960 s and 1970 s, teachers began to think of a curriculum which included, for example, elements of personal and social education, work experience, and pre-vocational education and which was broader than what was examined by the examination boards. They began to recognise levels of achievement (e.g., elementary levels of achievement in languages discontinued at age fourteen) which ought to receive recognition. Simultaneously, they began to realise the importance of children's motivation and self-esteem as providing them with a properly attested acknowledgement of their capabilities. Employers, too, indicated that they were interested in having information about a wider range of capabilities than were reflected in examination certificates.

During the 1970s and 1980s, a number of independent initiatives sought to respond to these needs. Although these varied widely in approach, they had what the PRAISE evaluation suggests was a common aim and "an increasingly coherent philosophy." The aim was "to provide school leavers of all levels of attainment with a positive statement of achievement across a range of activities." The philosophy is characterised as follows:

This emphasised assessment as part of the educational process and made pupils equal partners with teachers by giving them a prominent and active role. It also emphasised a need for positive, constructive, detailed and useful records which would support learning in school and help the school leaver to provide employers, trainers and other potential 'users' with the kind of information they required. Above all, it emphasised that the processes of recording should develop the self-concept, self-confidence and motivation of young people in such a way that they could gain the maximum benefit from their education.

These characteristics remained central to the development of RPAs in the government draft policy statement of November 1983 and the subsequent DES/Welsh Office (1984) publication "Records of Achievement: A Statement of Policy" according to which the purposes of RPAs were:

- to recognise, acknowledge and give credit for what pupils have achieved and experienced, not just in terms of results in public examinations but in other ways as well;

- to contribute to pupils' personal development and progress by improving their motivation, providing encouragement and increasing their awareness of strengths, weaknesses and opportunities;

- to help schools identify the all round potential of their pupils and to consider how well their curriculum, teaching and organisation enable pupils to develop the general, practical and social skills which are to be recorded;

- to provide young people leaving school or college with a short, summary document or record which is recognised and valued by employers and institutions of further and higher education. 
By 1984, a number of local authorities were already beginning to develop records of achievement, but this initiative was given a boost by the Education (Grants and Awards) Act 1984 which established a fund to support pilot schemes in nine local education authorities (LEAs), of which one was in Suffolk.

These LEA schemes were allowed some flexibility within the framework provided by the general objectives and criteria. Within each LEA, too, there were variations rooted in the particular character and starting point of the school. At the centre of what the schemes meant in practice to schools, however, were the following activities:

- preparatory work, including individual and group activities, in form tutor periods or in personal and social education lessons encouraging pupils to think about themselves, their capabilities, and their achievements and to start putting written material in a file or folder;

- one-to-one interviews between teacher and pupil aimed at putting together the pupil's own record, looking at this alongside teacher's perspectives, discussing differences, "negotiating" an agreed statement;

- teachers negotiating with local employers the acceptability of the record in place of a standard reference and pupils using the record of job interviews.

The implementation of this practice, of course, raised many severely practical questions including finding time for one-to-one interviews, equipping teachers with new skills, changing employers' expectations, and so on. Mixed with these were interesting issues of a more philosophical character having to do with the ethics of positive reporting, authenticity and honesty in self-reporting, the epistemology of a "negotiated" statement and the distinction between negotiation and dialogue, problems in the aspiration to holistic assessment, and the conceptualisation of the relationship between assessment and curriculum.

\section{Positive reporting}

The records have always been presented as records of achievement (and not of failure) with the function of encouraging a positive self-concept and developing self-confidence, self-esteem, and motivation among young people. It has, therefore, been an important point of principle that the records and reporting should be in positive terms.

This approach raises a number of interesting issues. In terms of children's perception of themselves, there are worries about the extent to which they might be led into a view of themselves which, albeit optimistic and encouraging, is illusory. I recall a lecturer in the United States quoting evidence which showed that children referred to their parents more than anyone else for careers advice and, then, evidence that $75 \%$ of parents thought their children were in the top $25 \%$ of the ability range. Presumably this provided the context for some optimistic, supportive, and encouraging advice about career futures. Presumably, too, it led to some shock and confusion when the realities emerged (which is not to say that these realities were exactly as portrayed in the given figures). 
It seems that there are certain things that we should certainly seek to do better in schools which lie behind the desire for positive reporting:

(a) we should avoid subjecting children to structures which are designed to give children unnecessary experience of failure (e.g., exams in which we know they will only get 20 marks out of 100 );

(b) we should demonstrate and help children to understand that their personal value as human beings is not conditional or dependent upon their success in school, let alone school tests;

(c) we should value and acknowledge in the school community positive qualities which they demonstrate outside the school curriculum.

But should we not also support and assist them in identifying and overcoming significant weaknesses which will be an obstacle to their pursuit of their own goals for the future? This point is crucial. If we are not open with children about deficiencies which are going to matter to them, we do not make it easy for them to do anything about them. We, thus, comfort them in the present at the price of disabling them for the future.

The real point is that there are very different ways of articulating and dealing with children's weaknesses. The best teachers can discuss these sensitively, kindly, constructively with a view to supporting their pupils in recognising them without being crippled by them and with a view to building an educational programme which will deal with them. In the worst ones, though humanly understandable, pupils' weakness or underachievement is presented as the just punishment for laziness or neglect, and pupils' humiliation is enjoyed as the teacher's revenge for his or her own months of frustration and defeat in the classroom.

The goal must be for pupils to have a picture of whatever most nearly passes as the truth of the situation, but that this should be presented supportively and with the prospect of continuing opportunity for development. This concern has led some people to modify the principle of positive reporting and to distinguish between the recording process (an activity between pupil and teachers) and the reporting process between pupil and teacher on the one hand and employer on the other. The first-the formative process-should include negative and positive observations; the second-the summative document-should be expressed exclusively in terms of positive achievement. This still leaves some problems however. There are, for example, questions about the honesty of such developments. Philosophers and lawyers distinguish between two forms of untruthfulness: the expression of falsehood and the suppression of truth. The exclusively positive report may not be untruthful in the first sense, but what about the second? "There are lies, damned lies and ROAs!" complained one tutor. $^{7}$

Then there are questions about the employer's right to know. There are many contexts of employment in which a worker's inattentiveness, unpunctuality, or lack of numeracy may easily put the health, safety, or welfare of others at risk. If the report contains no reference to any of these weaknesses, what is the employer to assume? Should he or she be left to make assumptions, or test applicants in the inadequate setting of an interview?

Finally, as we are beginning to see, the report becomes a puzzling form of communication with the employer almost bound to engage in a curious and almost certainly unreliable form of what some teachers enjoyed referring to as 
"interlinear literacy," or reading between the lines. Though some employers pride themselves on their ability to read between the lines, this is clearly a precarious form of communication, as this story told by a Suffolk teacher illustrates:

I was a little concerned that when looking at the tutor review many of the employers smiled at what they saw to be coded messages. In some cases, they were right, "highly individualistic approach" did mean that the boy in question is a "bit of a rebel". But very often they were reading more into the review than was really there. Each appeared to pick up a different clue from it, and once started on a particular track there was a tendency to look for clues to reinforce the view. In one case the employer took "Karen is a forceful girl, prepared to speak her mind" to mean that she is a bit "bolshy" and will dig her heels in," and later in that tutor review he reinforced that by taking "Karen has a tight circle of friends" to mean that this bolshiness has led to her relative isolation. From his point of view, that was consistent. In fact, I wrote that particular review and this interpretation was simply wrong. Perhaps the error is mine for laying a false trail. Whatever, it is clear that employers have the view that teachers are experts in providing hidden clues. Some are, but many are much more direct. ${ }^{8}$

There are problems enough in successfully communicating to someone else the truth as we see it. We inevitably compound these in only seeking to communicate one part of the truth and in leaving them to guess at what we might have said or have said by implication about the rest.

\section{Authenticity}

Any form of assessment invites one form or another of teaching (or learning) to the test. Indeed, one criterion against which we should evaluate any system of assessment is the consideration of its likely impact upon those who may allow their educational practices to be determined narrowly by its demands (see section 7 below). Records of achievement (such as university application forms) which ask about outside interests tempt pupils to behave to the test-to take on (superficially, at least) interests of the kind which might be thought to please employers. The corollary is that pupils may feel obliged to suppress or at least keep quiet about interests which they suspect-rightly or wrongly-employers will hold against them. (Do you declare that you are secretary of the local branch of the Young Socialists, or that you are an active member of CND?) Bringing extra-curricular interests into the domain of reportable assessment risks, then, both the distorting of motivation (intrinsic interest becomes contaminated by instrumental interest) and a kind of other-directedness about what interests it is appropriate, perhaps, not merely to declare, but to have.

\section{Getting an agreed statement}

One late stage in the process of producing the RPA in many models involves pupil and teacher coming together on the basis of their separately produced documents, accounts profiles, or assessments to "negotiate" (that is the commonly used term) an agreed statement. The one-to-one meetings have been one of the aspects of the RPA pilots to which teachers and pupils have responded most positively, ${ }^{9}$ although some have themselves raised questions about the element of negotiation: 
- "Whilst the benefits of the interview are clear it seems very doubtful that much 'negotiation' takes place at the moment."10

- "Completion of the 'statement' appeared to be the most difficult aspect from both staff and students' points of view."11

- "There has been little preparation for negotiated assessment and this has proved difficult for staff and students." 12

It is worth asking why a single statement needs to be negotiated at all. The reduction of two statements provided from the clearly separate and not surprisingly different perspectives of teacher and pupil into one statement emanating from somewhere between the two may not improve the quality of data available. In other fields, naturalistic researchers have acknowledged and celebrated the "illumination" provided by a multi-perspective reporting. Why not extend this to pupil profiling? ${ }^{13}$

It is worth questioning, too, whether what goes on between pupils and teacher ought properly to be described as a "negotiation." It has been suggested 14 that "dialogue" is perhaps a more appropriate form for what, in aspiration at least, should be going on. Negotiation is about what people will allow; dialogue about what is true. The determinants of the outcome of negotiation are the power of the respective negotiators, their negotiating skills or cunning, and the strength of their commitment to their own positions. As James points out, "to talk of negotiating the validity or truth of accounts with participants implies a consensus theory of truth that is naive and relativistic." 15

By contrast, the determinants of the outcome of a dialogue (at least in the ideal type) are the reasons, arguments, and evidence adduced by either party and their intellectual and emotional receptivity to them. James has observed that

the ground for an interpretation or judgement needs to be scrutinized and this is not a matter for negotiation. It is an epistemological activity, concerned with meaning, understanding and the ascription of value. In this context, the term "dialogue," with all its Socratic associations, seems more appropriate. ${ }^{16}$

The Fourth Cambridge conference on Educational Evaluation argued that:

When we are looking at pupil assessment, we should be concerned with better understanding of the pupil's achievements and person, with, in some sense, the truth or validity of statements made and not merely with what assessment can be arrived at on the basis of a process of exchange of gifts and concessions. ${ }^{17}$

This, of course, oversimplifies the character of a real discussion between teacher and pupil bound by very unequal power relations. This example drawn from the national evaluation report has, perhaps, a familiar ring:

"Disagreements," or polite differences of opinion, were dealt with with much embarrassment on both sides, especially where the tutor's assessment was less positive than the pupil's. The solution to these differences was always initiated by the tutor and tended either to be a provisional compromise pending further interview, or the teacher's own assessment prevailing. ${ }^{18}$ 
The notion of dialogue articulated here may, however, operate as an aspiration or as a criterion against which the development of some of these early stumbling attempts can be measured.

\section{The holistic profile}

The decision about what to assess, record, profile, or report is, of course, very significantly an evaluative one. It speaks of what ingredients of human personality or achievement we take to be significant, or at least educationally significant, in general or in a particular context. Part of the history of RPAs, as I have described it, is the story of attempts to gain recognition for pupil attainments outside the more narrowly academic, GCE/CSE tested, curriculum. The national evaluation team reported that "most of the schools we have studied aimed in their ROA systems to portray the 'whole person' " and that "our evidence points to general and steady progress towards the creation of ROA systems, at school level, which aim to provide an holistic view of the individual based on recording achievement across the whole curriculum and outside it as well." 19 The motives for this have included the concern that educationally we have addressed and valued only a single dimension of human personality and the view that we should adopt a more holistic approach in both curriculum and assessment. But, of course, this aspiration raises profound questions in both philosophy and education. In particular, it is clear that any view as to what are the elements of the "whole" being is problematic. Part of the problem is the issue of differentiation, i.e., how many dimensions of description does one need to portray the personality of the "whole child"? ${ }^{20}$ Bee organizes her book The Developing Child ${ }^{21}$ by dividing the 'whole child' into three realms: physical, thinking, and social. Clearly these are capable of many sub-divisions, and are they really discreet? As Smith and Klass point out, the most extreme case of this differentiation issue is the controversy over intelligence. The Standard Binet test gives a single " $\mathrm{g}$ " IQ score. At the other extreme, Guilford's "structure of the intellect" presents a 120 dimension model! Do we have to describe a child's achievement on 120 dimensions (of intelligence alone) before we can be said to have "captured" or done justice to the "whole child"?

Even if we could resolve this question, however, it is not obvious that all dimensions of personhood fall in the province of education, let alone schooling. Let us consider, for example, the nature of someone's sexuality, the strength of their sexual drive, their fertility-important enough, we might argue, to their human being, but should we see them rated on their school reports? Or what about a person's spiritual life, their oneness with or divorce from God, their coming to terms with mortality-hardly trivial matters if we are to look at people as a "whole"-but, again, it is not obvious that they have to be the focus of either the school curriculum or school assessment. There is life outside school; there are agents of personal development acting outside school; and, more controversially perhaps, growing individuals should be allowed to keep some parts of their lives out of the engrossing tentacles of the school curriculum and to themselves. (One child interviewed in relation to the RPA argued that parents should be more extensively involved. "But," she added, "not to the extent that they know everything you're doing!") Perhaps the pupil record, profile, or report should accept and recognise much more explicitly that it does not even attempt to "capture" the whole child. It reflects only certain aspects of the 
child's achievements and character selected as being the particular business of the school.

Of course, part of what has been happening through the pupil profiling movement has been precisely a programme for change in terms of what should be regarded as the business of the school. It represents among other things an attempt to consolidate some of the curriculum gains achieved in "the personal curriculum" in "personal and social education" and "active tutorial work" which have brought understanding of self, interpersonal relations, group work, values clarification, and so on into the school curriculum, but it had not yet been recognised through any formal system of assessment. The new claims on assessment reinforce increasingly well-established claims on the curriculum which are themselves supported by a somewhat unholy alliance of the counselling and "welfare" wing of the educational community on the one hand and, on the other, employers looking for a workforce qualified by an appropriate admixture of social grace, communicativeness, capability, and compliance.

Some of the early initiatives in recording pupil achievement (including the Suffolk one) left schools with a two-part system in which academic achievement was acknowledged in public examination certificates and other "personal" achievements in the record of achievement. This bi-partite structure, while more comprehensive in terms of the range of human personality encompassed, still offended against the holistic principle with which, I have suggested, they were concerned:

RPA must move on. RPA has been too pastoral orientated and suffers

because of it. It must become a more complete document for the student. ${ }^{22}$

What many of the schemes have achieved or are seeking to achieve is the bringing together of the two elements, the "academic" and the "pastoral" in a single recording and reporting system:

As soon as we have an academic profile working alongside the personal profile, RPA will become part of the curriculum in the way that it is not at present. At the moment there appear to be artificial divisions between the "pastoral" and the "academic" , but with the form tutor eventually using the same methods as the subject teacher, the two areas will be brought back together. 23

How coherent this bringing together will be in curriculum as well as assessment terms remains to be seen. What I hope to have indicated is that the nature and achievement of this "coherence" rests not merely upon overcoming organizational difficulties but also upon resolving conceptually the nature of the whole and the interrelationship of the parts which the profile seeks to capture.

\section{Assessment and Curriculum}

The profiling movement has highlighted an interesting question in the philosophy of the curriculum to do with the relationship between curriculum and assessment. Two such relationships are fairly familiar:

(i) curriculum led assessment in which curriculum is logically and chronologically established first and shapes and determines the character of a system of assessment which supports it;

(ii) assessment led curriculum in which by design or in practice teachers allow the demands of assessment to determine the curriculum-they "teach to the test." 
The national evaluation report provides a nice example of the way the changing demands of assessment can create changes in the curriculum, in this case in the area of "personal" achievement. "At Magnolia Girls' Grammar School staff felt that there was little validity in commenting on specific personal qualities if girls had not been provided with adequate in-school opportunities to demonstrate them (e.g., leadership). For this reason, a deliberate effort was made to create areas for responsibility and/or service. Thus, a list of possibilities was created (e.g., sorting archive materials for the history department) and girls were given an opportunity to volunteer." 24

The profiling movement offers a third alternative:

(iii) assessment as a curriculum in which the processes of assessment (and I have indicated that these extended processes) are themselves presented as supporting the learning which is desired in a curriculum which focuses on self. "It's almost as if the subject 'myself' has come into the curriculum." 25

The individual tasks of self-assessment, the group work, the one-to-one discussions with a class teacher have all a first function of helping pupils to reflect on, clarify, articulate, and record a richer understanding of themselves and their achievements. In the eyes of those promoting it, the value of this lies perhaps most significantly in the skills and understanding acquired through the process of getting there:

It helps you find out more about yourself. ${ }^{26}$

... the real benefit of RPA is the process that the students go through rather than the final product they end up with. Through the process they acquire a greater understanding of themselves. ${ }^{27}$

Part of what is so significant about records of pupil achievement is that-and in this they are unlike most systems of assessment employed in education - their primary audience and primary beneficiary is the child. In this sense, they may claim to offer an approach to assessment which is peculiarly, if not uniquely, an educative one. 


\section{Notes}

'D. Bridges, Records of Achievement: Local Evaluation Report (Ipswich: Suffolk LEA, 1987).

${ }^{2}$ P. Broadfoot, M. James, S. McMeeking, D. Nuttall, and B. Stierer, Records of Achievement: Report of the National Evaluation of Pilot Schemes (London: HMSO, 1988).

${ }^{3}$ Ibid.

${ }^{4}$ Ministry of Education, 1963, 240 pages.

5 Ibid., v. 1984).

${ }^{6} \mathrm{DES}$ and Welsh Office, Records of Achievement (London: HMSO,

${ }^{7}$ Broadfoot, et al., 1988, op. cit., 57.

${ }^{8}$ Bird, 1987, 42.

${ }^{9}$ See Bridges, op. cit., 39.

10. Law, A Case Study of the RPA Pilot Scheme in Suffolk: Thomas Mills High School (Ipswich: Suffolk LEA, 1987), 28.

${ }^{11}$ M. Hall, A Case Study of the RPA Pilot Scheme in Suffolk: Northgate High School (Ipswich: Suffolk LEA, 1987), 10.

12J. Dale, A Case Study of the RPA Pilot Scheme in Suffolk: Stowupland High School (lpswich: Suffolk LEA, 1987), 30.

${ }^{13}$ On this, see D. Bridges, J. Elliott, and C. Klass, "Performance Appraisal as Naturalistic Enquiry," Cambridge Journal of Education, 16(3), 1986.

${ }^{14}$ Ibid.

${ }^{15}$ M. James, "Negotiation and Dialogue in Student Assessment and Teacher Appraisal," in H. Simons and J. Elliott (eds.), Rethinking Appraisal and Assessment (Milton Keynes: Open University Press, 1989), 157.

${ }^{16}$ Ibid., 157.

${ }^{17}$ D. Bridges, J. Elliott, and C. Klass, op. cit., 226.

18p. Broadfoot et. al., op. cit., 32.

${ }^{19}$ Broadfoot $e t$. al, op. cit., 3.

${ }^{20}$ L.M. Smith and C. Klass, "Assessing the Whole Child," in H. Simons and J. Elliott (eds.), op. cit..

${ }^{21}$ H. Bee, The Developing Child (Third Edition) (New York: Harper Row, 1987).

22M. Hall, op. cit., 19.

23 J. Dale, op. cit., 37.

${ }^{24} \mathrm{~J}$. Broadfoot, et. al, op. cit., 17.

25 D. Bridges, op. cit., 64.

26J. Dale, op. cit., 4.

${ }^{27}$ Ibid., 24. 